\title{
AOR
}

Selected Papers of \#AolR2020: The $21^{\text {st }}$ Annual Conference of the Association of Internet Researchers Virtual Event / 27-31 October 2020

\section{LIFE AS A NETWORKED FAN}

Stephanie Garrison

University of Aberdeen

Naomi Jacobs

Lancaster University

\section{Introduction}

Research to understand the lives of fans has generally considered online fandom as fan community, such as communities of interest (Hills, 2015), knowledge communities (Jenkins, 2006) and interpretive communities (Sullivan, 2019). However, the facilitative nature of modern digital social networks mean that fans are now able to engage in fandoms without having to belong to a definable singular fan community and can spread their fannish interest across a multitude of social platforms and spaces within them.

Some scholars have suggested that online communities and/or fandoms are fragmenting (Delanty, 2018; Coppa, 2014; Hills, 2017; Larsen and Zubernis, 2012). Instead, we suggest that digital technologies facilitate new types of networks which are fan-centric rather than fan community-centric, and which extend offline. Incorporating decentralized practices such as lurking and fandom hopping which are less communitycentered, we propose that fans, rather than the fan communities, should be considered as the center of a network model of modern media fandom.

\section{Fans as networks}

In this work, we build on theories of social networks defined by sociologist Barry Wellman (Rainie \& Wellman, 2012) via several different case studies which the authors have carried out using ethnographic and survey methods.

Garrison S, Jacobs, N. (2020, October). Life as a Networked Fan. Paper presented at AolR 2020: The $21^{\text {th }}$ Annual Conference of the Association of Internet Researchers. Virtual Event: AolR. Retrieved from http://spir.aoir.org. 
These include;

1) Outlander fans who were selected for study as members of a particular Facebook group, but who often participate simultaneously in multiple fan spaces both online and offline. Different forms and levels of interaction were observed depending on the strength of their network ties within each space. This ranges from online participation with micro-fandoms to offline activities in the form of fan tourism to Scotland.

2) Fans of Supernatural who take live-stream footage at conventions. These individuals were seen to act as a nexus point between online and offline fan groups and individuals, by co-existing in both spaces.

3) Intergenerational knowledge-sharing in Doctor Who fans facilitated by a new space for engagement, the Twitch-based live-streaming of classic episodes. The level of fan engagement was observed to be heterogeneous, with some fans viewing and not participating, some using it to facilitate offline networks and interactions, some participating in real-time online discussions, and some extending this participation into other online communities and spaces such as Twitter.

These examples demonstrate how individuals form networks around themselves which extend into multiple online and offline spaces, creating a multilayered personal interaction space.

\section{Implications - different lives in different platforms}

Our case studies illustrate cases where fans have personal networks which span different platforms and spaces of fan community and fan expression both online and offline. A fan may have affective ties which connect them to individual media texts, as well as to social fan milieus online or offline. These latter may be networks of social engagement (micro-fandoms) but not necessarily contiguous with the wider 'community' surrounding a media text itself (macro-fandoms). This concept of the networked individual can be more generally applied to life in digital society, and the multidimensional nature of our lives across the online spaces we inhabit. In addition to the idea of context collapse and multiple presentations of self (Marwick and boyd 2010) we suggest that individuals may draw different value from different connections and activities within their own network.

Fan communities have historically congregated sequentially on different digital platforms, with identifiable 'migrations' occurring for a variety of reasons (Dym and Fiesler 2018, Fiesler 2018). However, we have also seen in our case studies that fans may exist in several different micro-communities simultaneously, across multiple platforms, and may exhibit different behaviors within them. Fans may move between several different micro-fandoms within a single or across multiple macro-fandoms, with different forms of interaction and behaviors depending on the nature of their network ties to each. Cross-fertilization on multi-fandom platforms such as Tumblr may be making it easier for individuals to discover and join new macro-fandoms, as they examine the individually curated spaces of other fans. 
Costa (2018) provides an example of how platform architectures can be utilized differently in different cultural contexts, describing social media users in Turkey who create multiple Facebook accounts and rigorously constructed privacy settings to keep social groups distinct. By doing this, they are using the platform in a way that was not intended by the designers, to create their own affordances-in-practice. Fan communities have a similar history of such appropriation, for example, Tumblr users in fandom have developed a discourse function in the tagging system (Borlai, 2018), echoing the complex tag usage on Delicious which was destroyed by a design update that removed this unintended functionality (Cegłowski, 2013). These affordances-in-practice, both intended and appropriational, may change how an individual behaves in each space that is part of their network.

\section{Conclusion}

Based on our research to date, we suggest that different behaviors and social norms are attached to different platforms, and arise as an ongoing constructional combination between the needs of the individual, the desires of the community, and the design of the digital spaces themselves. For example, the granular privacy settings and text-centric community structuralization available on Livejournal and Dreamwidth creates different opportunities for affordances than Tumblr, which lacks them. Costa suggests that "affordances are not intrinsic properties that can be defined outside their situated context of usage, but ongoing enactments by specific users that may vary across space and time" (Costa, 2018 p. 3653). We propose that future work should interrogate how policies related to such communal digital spaces, both written and socially constructed, impact upon individual and community behavior online and offline. This has implications for the design and policy design of new platforms.

\section{References}

Bourlai, E. E. (2018). 'Comments in Tags, Please!': Tagging practices on Tumblr. Discourse, context \& media, 22, 46-56.

Cegłowski, M. (2013) Fan is A Tool-Using Animal. Presented at the 2013 dConstruct conference Brighton, UK. Text available at https://idlewords.com/talks/fan is a tool using animal.htm

Coppa, F. (2014). Fuck yeah, Fandom is Beautiful. The Journal of Fandom Studies, 2(1), 73-82. https://doi.org/10.1386/jfs.2.1.73 1

Costa, E. (2018). Affordances-in-practice: An ethnographic critique of social media logic and context collapse. New Media \& Society, 20(10), 3641-3656.

Delanty, G. (2018). Community: Third edition (Third Edition). Routledge. 
Dym, B., \& Fiesler, C. (2018). Generations, migrations, and the future of fandom's private spaces. Transformative Works and Cultures, 28.

Fiesler, C. (2018) Survey results: Fan Platform Use over Time. https://cfiesler.tumblr.com/post/171831912875/survey-results-fan-platform-use-over$\underline{\text { time }}$

Hills, M. (2015). The expertise of digital fandom as a 'community of practice': Exploring the narrative universe of Doctor Who. Convergence: The International Journal of Research into New Media Technologies, 21(3), 360-374.

https://doi.org/10.1177/1354856515579844

Hills, M. (2017). From Fan Culture/Community to the Fan World: Possible Pathways and Ways of Having Done Fandom. Palabra Clave - Revista de Comunicación, 20(4), 856-883. https://doi.org/10.5294/pacla.2017.20.4.2

Jenkins, H. (2006). Convergence culture: Where old and new media collide. New York University Press.

Larsen, K., \& Zubernis, L. (Eds.). (2012). Fan culture: Theory - practice. Cambridge Scholars Publ.

Marwick, A. E., \& boyd, d. (2011). I tweet honestly, I tweet passionately: Twitter users, context collapse, and the imagined audience. New media \& society, 13(1), 114-133.

Rainie, H., \& Wellman, B. (2012). Networked: The new social operating system. MIT Press.

Sullivan, J. L. (2019). Media audiences: Effects, users, institutions, and power (Second edition). SAGE. 